Volume 21 Number 6 I pp. 533-537 I (c) The Author(s) 2018. This is an Open Access article, distributed under the terms of the Creative Commons Attribution-NonCommercial-NoDerivatives licence (http://creativecommons.org/licenses/by-nc-nd/4.0/), which permits non-commercial re-use, distribution, and reproduction in any medium, provided the original work is unaltered and is properly cited. The written permission of Cambridge University Press must be obtained for commercial re-use or in order to create a derivative work. I doi:10.1017/thg.2018.60

\title{
Human Genetics Society of Australasia Position Statement: Genetic Testing and Personal Insurance Products in Australia
}

\author{
Ainsley J. Newson, ${ }^{1}$ Sam Ayres, ${ }^{2,3,4}$ Jackie Boyle, ${ }^{5}$ Michael T. Gabbett, ${ }^{6,7}$ and Amy Nisselle ${ }^{4,8,9}$, on \\ behalf of the Education, Ethics and Social Issues Committee of the Human Genetics Society of \\ Australasia \\ ${ }^{1}$ The University of Sydney, Faculty of Medicine and Health, Sydney School of Public Health, Sydney Health Ethics, Sydney, \\ New South Wales, Australia \\ ${ }^{2}$ Victorian Clinical Genetics Services, Murdoch Children's Research Institute, Melbourne, Victoria, Australia \\ ${ }^{3}$ Melbourne Genomics Health Alliance, Melbourne, Victoria, Australia \\ ${ }^{4}$ Australian Genomics Health Alliance, Melbourne, Victoria, Australia \\ ${ }^{5}$ Genetics of Learning Disability Service, Waratah, New South Wales, Australia \\ ${ }^{6}$ Institute of Health and Biomedical Innovation \& School of Biomedical Sciences, Queensland University of Technology, \\ Brisbane, Queensland, Australia \\ ${ }^{7}$ School of Medicine, Griffith University, Gold Coast, Queensland, Australia \\ ${ }^{8}$ Genomics in Society, Murdoch Children's Research Institute, Melbourne, Victoria, Australia \\ ${ }^{9}$ Faculty of Medicine, The University of Melbourne, Melbourne, Victoria, Australia
}

The expansion of genetic and genomic testing in clinical practice and research and the growing market for at home personal genome testing has led to increased awareness about the impact of this form of testing on insurance. Genetic or genomic information can be requested by providers of mutually rated insurance products, who may then use it when setting premiums or determining eligibility for cover under a particular product. Australian insurers are subject to relevant legislation and an industry standard that was updated in late 2016. In 2018, the Human Genetics Society of Australasia updated its position statement on genetic testing and life insurance to account for these changes and to increase the scope of the statement to include a wider scope of insurance products that are not rated according to community risk, such as life, critical care, and income protection products. Recommendations include that providers of professional education involving genetics should include ethical, legal, and social aspects of insurance discrimination in their curricula; that the Australian government take a more active role in regulating use of genetic information in personal insurance, including enacting a moratorium on use of genetic test results; that information obtained in the course of a research project be excluded; and that there is improved engagement between the insurance industry, regulators, and the genetics profession.

Keywords: genetic testing, genomics, insurance, discrimination, regulation, Australia

\section{Background}

This position statement provides the stance of the Human Genetics Society of Australasia (HGSA) on the use of information obtained from genetic or genomic testing in the underwriting process for life, critical illness, and income protection insurance products (personal insurance products). Relevant definitions are as follows:

- Genetic testing may result in the diagnosis of a genetic condition or provide information about the chance of an asymptomatic person developing a genetic condition in the future.

ReCEIVED 27 September 2018; ACCEPTED 3 October 2018. First published online 21 November 2018 .

ADDRESS FOR CORRESPONDENCE: Ainsley Newson, Faculty of Medicine and Health, Sydney School of Public Health, Sydney Health Ethics, University of Sydney, Level 1, Medical Foundation Building K25, 92-94 Parramatta Road, University of Sydney, NSW 2006, Australia. E-mail: ainsley.newson@sydney.edu.au 
- Genomic testing includes whole exome and whole genome sequencing. It involves use of high throughput, massively parallel sequencing methods.

- Genetic information includes personal medical history information, family medical history information, and the results of individual or familial genetic or genomic tests.

In this position statement, 'genetic testing' refers to all types of genetic testing, including genomic testing; and 'genetic information' refers to all types of information gained from genetic or genomic testing.

\section{Pathways to Obtaining Genetic Information}

A schematic of the pathways to obtaining genetic information is provided in Table 1. As this shows, there are various types of genetic testing that can be accessed for a range of reasons. Tests are accessed through both publicly funded healthcare services and commercial providers, the latter of which may supply tests without involving a health professional.

Table 1 also shows the diverse findings that can arise from a genetic test. Current knowledge is used to interpret these findings. As knowledge develops, interpretation of findings can change, potentially altering their clinical significance. All of these factors can add complexity to underwriting (discussed further below).

\section{Personal Insurance Products}

Issuing many personal insurance products (mutually rated products) involves an assessment of the applicant's individual risk factors, including their family history and personal health status. This process is known as 'underwriting. It is thought that less than $40 \%$ of Australians hold personal life insurance products and less than $20 \%$ hold other personal insurance products (Canstar, 2016). Other insurance products, such as private health insurance and some forms of personal insurance provided by superannuation funds, are community rated. This means that policyholders pay the same premium regardless of their individual health status or risk factors.

Under section 21 of the Insurance Contracts Act 1984 (Cth), all applicants for personal insurance products are required to disclose information to insurers that will be relevant to the insurer's decision whether to accept the risk of insuring the individual. That is, insurance contracts must be made in 'good faith'. In practice, this means that applicants for insurance must answer all questions posed by insurers honestly and fully.

\section{Genetic Information and Insurance}

In Australia, genetic information may impact an individual's ability to obtain personal insurance products, or increase the premium paid. The request for, and use of, genetic information by insurers is governed by legislation

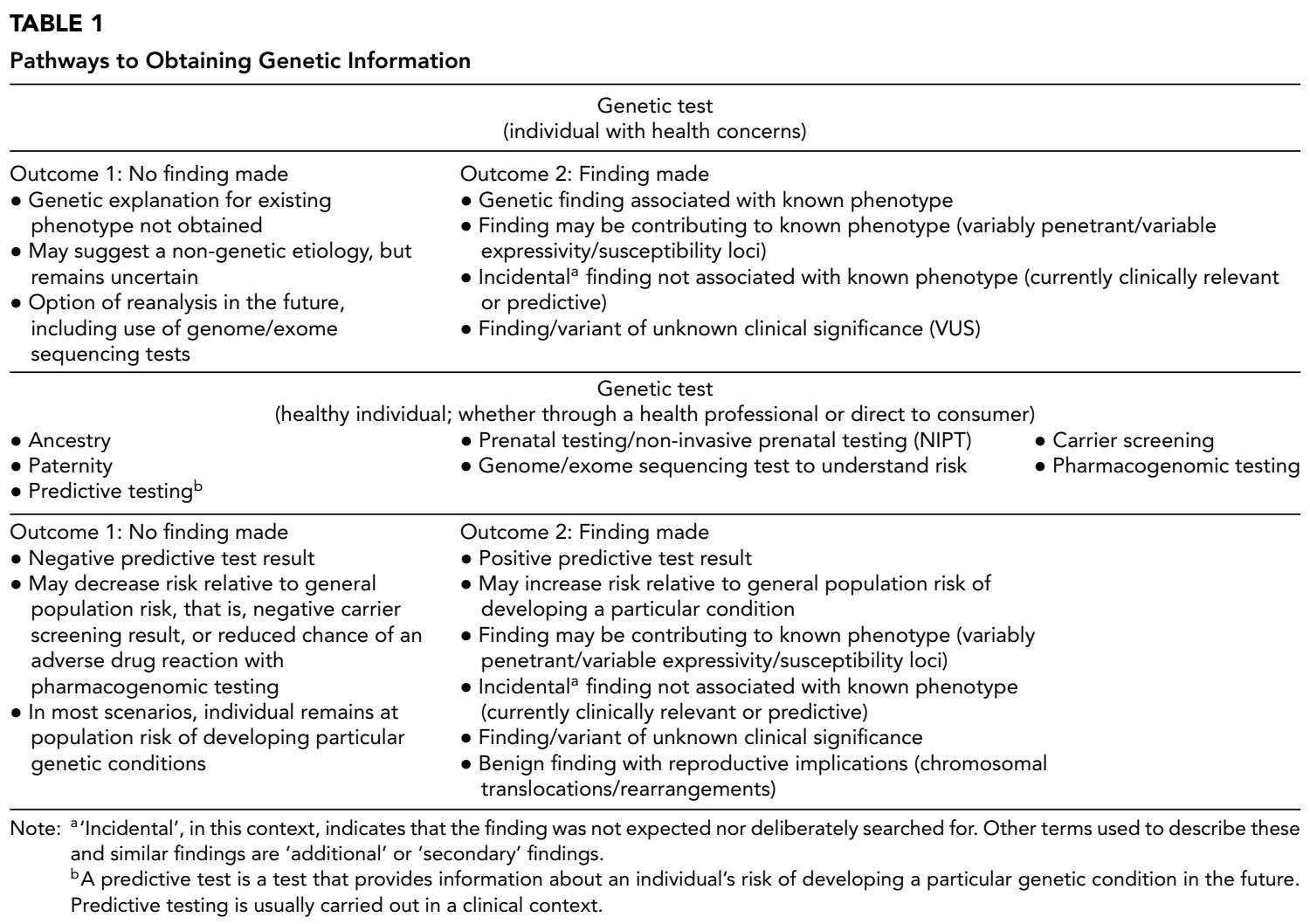


and an industry policy. The Disability Discrimination Act 1992 (Cth) prevents discrimination based on genetic status. However, there is a wide exemption under section 46, which means that insurers are exempt from the prohibition on discrimination if they can substantiate an underwriting decision with reasonable data. Note that an applicant's family medical history can also lead to an increase in premiums for personal insurance products.

Australia's Financial Services Council (FSC) has published two voluntary industry standards: a Genetic Testing Policy (FSC, 2016a) and a Family History Policy (FSC, 2016b). Both standards were updated in late 2016. These standards are not binding and do not apply to insurers who are not members of the FSC. Under these Standards

(a) an applicant for a personal insurance product should not be required to have a genetic test;

(b) risk assessments associated with results of genetic testing should take into account the potential benefits of screening, early diagnosis, or treatment;

(c) clear reasons for underwriting decisions should be provided;

(d) if an application is rejected, alternative terms or products should be considered for offer instead;

(e) if requested, an applicant is required to disclose known genetic test results to the insurer, regardless of whether they were obtained via clinical testing, research (discussed further below), or direct to consumer personal testing;

(f) if requested, an applicant is required to disclose any diagnosis of a genetic condition in a first-degree relative (i.e., a parent, sibling, or child). However, an applicant is not required to disclose any relative's predictive genetic test result. ${ }^{1}$

\section{The HGSA's Position on Using Genetic Information in Insurance}

\section{General Considerations}

The usual aim of genetic testing is to obtain genetic information for the improved health and wellbeing of the individual being tested, or (in the context of research) to benefit the future health of the population. Genetic testing can also be undertaken to benefit another family member, such as testing to clarify a diagnosis or determine the significance of a gene change, known as a 'genetic variant', in the other family member. Long-term benefits to individuals, their families, the community, and insurers result when genetic testing and subsequent risk-reducing behaviors or interventions can mitigate or ameliorate the consequences of inherited disorders.

While genetic testing may reveal an increase in an individual's risk of developing a genetic condition, it can also serve to reduce or negate an individual's risk compared to family history alone. This occurs when testing shows that the individual has not inherited a genetic variant present in other family members. Even if genetic testing confirms an individual is at higher risk, it will usually be impossible to predict accurately the age of onset of the condition, its rate of progression, its severity, life expectancy, or whether the person will ever develop the condition. The onset or severity of symptoms of many genetic conditions can also be avoided or mitigated by changing health or lifestyle behaviors. Individuals may choose to undergo genetic testing primarily for the benefit of other family members, electing not to receive results themselves.

Genetic discrimination has occurred in Australia and remains a significant concern of those seeking testing (Keogh \& Otlowski, 2013). Fears of insurance discrimination should not prevent individuals from accessing clinically indicated genetic testing.

\section{Recommendations}

1. The HGSA urges those developing curricula and other professional education materials involving genetic testing to incorporate materials relating to the ethical, legal, and policy considerations associated with the use of genetic information in assessments for personal insurance products.

2. The HGSA urges the Australian Federal Government to take a more active role in regulating the use of genetic information in insurance, for example, to ensure that any discrimination that does occur adheres to the relevant provisions of the Disability Discrimination Act 1992 (Cth). The wide exemption granted by this Act should also be reconsidered.

3. The HGSA urges regulators and insurers not to require disclosure of genetic testing undertaken as part of a research project. Research studies are often exploratory, meaning that findings may not be replicated. There is also evidence that fear of insurance ramifications negatively impacts rates of research participation (Keogh et al., 2009), which may impede implementation of genomics in the future.

4. Until genetic information gleaned from research is excluded, researchers and human research ethics committees should ensure that the potential implications of research participation for obtaining personal insurance products in the future are clearly explained to participants.

5. A moratorium is needed. The HGSA requests regulators and insurers implement a moratorium on the use of genetic test results, pending improved actuarial estimates of the impact of such information on adverse selection. $^{2}$

6. If an individual chooses to undergo genetic testing and receives a result that returns the individual to population-level risk, they should be able to use this result to negate relevant family history information, as is the case under the United Kingdom's Code of Practice 
(HM Government and Association of British Insurers, 2018).

7. While this moratorium is in place, the HGSA advocates for close liaison between regulators, the insurance industry, and the genetics profession to more accurately interpret genetic information and its implications (including the potential for risk-mitigating interventions) when calculating the overall health risk for individuals.

8. The HGSA encourages insurers to continue to review actuarial modeling of the impact of predictable genetic conditions. The HGSA wishes to promote trust and confidence between genetic health professionals and insurers and encourages the industry to seek statistical, molecular, and epidemiological information from geneticists and bioinformaticians who have relevant expertise.

In calling for a moratorium, the HGSA acknowledges the concern that genetic information could potentially be used to engage in adverse selection against insurance companies (Vukcevic \& Chen, 2017). However, the HGSA also notes that there is limited evidence to support this claim (Newson et al., 2017). Further, the HGSA asserts that the number of conditions to which adverse selection can currently apply is very small, with low population prevalence.

\section{Counseling Considerations}

Any decision by a patient or consumer to undertake a genetic test should include time to consider the implications of having the test. The HGSA encourages all genetic health professionals to understand the potential implications of genetic testing for individuals considering purchasing personal insurance products. Genetic health professionals should raise the potential insurance implications of genetic information with those seeking genetic testing when, in their professional judgment, it is appropriate to do so (Centre for Genetics Education, 2017). This may include (but is not limited to)

1. for individuals with a family history of a genetic condition, family history alone is likely to impact an application for personal insurance products;

2. genetic testing can either confirm an individual's family history, or return the individual to population-level risk;

3. for individuals with no family history of a genetic condition, there is a possibility that testing may reveal a previously unknown genetic variant, which may impact any applications for personal insurance products;

4. individuals have an obligation to disclose genetic test results to insurers when applying for life insurance products.

Companies based in Australia offering 'onshore' genetic testing directly to consumers should also ensure that potential insurance implications, such as those outlined above, are clearly explained to consumers as part of the information provided with the test.

\section{Acknowledgments}

We thank the additional members of the Education, Ethics, and Social Issues Committee of the Human Genetics Society of Australasia: Kate Dunlop, Bronwyn Terrill, and Jacqueline Savard. This statement was reviewed and approved by the HGSA Council in March 2018. A minor change was made in October 2018 to note the United Kingdom's move from a Moratorium to a Code of Practice. We also thank Ms Jane Tiller for her advice during the drafting of this position statement.

\section{Endnotes}

1 The authors thank Ms Jane Tiller for suggesting that Clause (f) be included and for her assistance with wording. See Table 1 for a definition of 'predictive'.

2 In March 2018, the Parliamentary Joint Committee on Corporations and Financial Services handed down its report into the Life Insurance Industry (Parliament of Australia, 2018). This report makes several recommendations, including to assess the impact of a moratorium on the use of predictive genetic test results in life insurance. The HGSA welcomes this report and looks forward to implementation of its findings.

\section{Financial Support}

The open access publication of this Position Statement has been supported by the University of Sydney, through a Sydney Medical School Accelerator Fellowship awarded to Ainsley Newson.

\section{Conflict of Interest}

None.

\section{Ethical Standards}

Not applicable.

\section{References}

Canstar. (2016). Life insurance - Are you underinsured? Retrieved from https://www.canstar.com.au/life-insurance/ life-insurance-are-we-underinsured/

Centre for Genetics Education. (2017). Fact Sheet 20: Life Insurance Products and Genetic Testing. Retrieved from http://www.genetics.edu.au/publications-and-resources/ facts-sheets/fact-sheet-20-life-insurance-products-andgenetic-testing-in-australia

Financial Services Council (FSC). (2016a). FSC Standard No 11 Genetic Testing Policy. Retrieved from https://www.fsc.org.au/resources/standards/11s-genetictesting-policy-final.pdf 
Financial Services Council (FSC). (2016b). FSC Standard No 16 Family Medical History Policy. Retrieved from https://www.fsc.org.au/resources/standards/16s-familyhistory.pdf

HM Government and Association of British Insurers. (2018). Code on Genetic Testing and Insurance. Retrieved from https://www.gov.uk/government/publications/codeon-genetic-testing-and-insurance

Keogh, L. A., \& Otlowski, M. F. (2013). Life insurance and genetic test results: A mutation carrier's fight to achieve full cover. Medical Journal of Australia, 199, 363366.

Keogh, L. A., van Vliet, C. M., Studdert, D. M., Maskiell, J. A., Macrae, F. A., St John, D. J., ... Jenkins, M. A. (2009). Is uptake of genetic testing for colorectal cancer influenced by knowledge of insurance implications?. Medical Journal of Australia, 191, 255-258.

Newson, A. J., Tiller, J., Keogh, L. A., Otlowski, M., \& Lacaze, P. (2017). Genetics and insurance in Australia: Concerns around a self-regulated industry. Public Health Genomics, 20, 247-256. doi:10.1159/000481450

Parliament of Australia. (2018). Report on the Life Insurance Industry. Retrieved from https://www.aph.gov.au/ Parliamentary_Business/Committees/Joint/Corporations_ and_Financial_Services/LifeInsurance/Report

Vukcevic, D., \& Chen, J. (2017). Thinking about life insurance through a genetic lens. Paper presented at the Actuaries Summit, Melbourne. 